\title{
Mental Health Burden in Different Professions During the Final Stage of the COVID-19 Lockdown in China: Cross-sectional Survey Study
}

Junfeng Du ${ }^{1,2^{*}}$, MSc; Gwendolyn Mayer ${ }^{2 *}$, DipPsych; Svenja Hummel²; Neele Oetjen ${ }^{2}$, MSc; Nadine Gronewold $^{2}$, MSc; Ali Zafar ${ }^{2}$, MA, MSc; Jobst-Hendrik Schultz², PD, Dr med

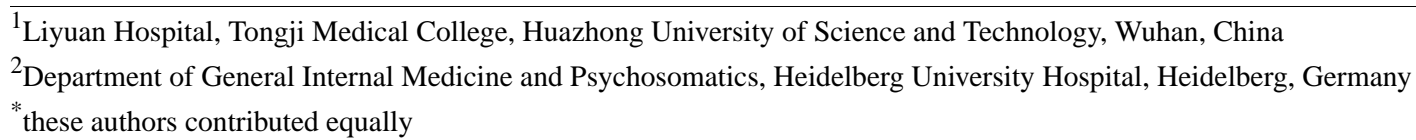

Corresponding Author:

Gwendolyn Mayer, DipPsych

Department of General Internal Medicine and Psychosomatics

Heidelberg University Hospital

Im Neuenheimer Feld 130.3

Heidelberg, 69120

Germany

Phone: 4962215635685

Fax: 496221567505

Email: gwendolyn.mayer@med.uni-heidelberg.de

\section{Abstract}

Background: COVID-19 resulted in considerable mental health burden in the Chinese general population and among health care workers at the beginning and peak of the pandemic. However, little is known about potentially vulnerable groups during the final stage of the lockdown.

Objective: The aim of this survey study was to assess the mental health burden of different professions in China in order to find vulnerable groups, possible influencing factors, and successful ways of coping during the last 4 weeks of the lockdown in Hubei Province.

Methods: A cross-sectional online survey asked participants about current residence, daily working hours, exposure to COVID-19 at work, and media preferences. We used a shortened version of the Depression, Anxiety and Stress Scale (DASS-21) to assess mental health. Further assessments included perceived stress (Simplified Chinese version of the 14-item Perceived Stress Scale), coping strategies for all participants, and specific stressors for health care workers. We followed the reporting guidelines of the STROBE (Strengthening the Reporting of Observational Studies in Epidemiology) statement for observational studies.

Results: The sample ( $\mathrm{N}=687)$ consisted of 158 doctors, 221 nurses, 24 other medical staff, 43 students, 60 teachers/government staff, 135 economy staff, 26 workers/farmers, and 20 professions designated under the "other" category. We found increased depression $(n=123,17.9 \%)$, anxiety $(n=208,30.3 \%)$, and stress $(n=94,13.7 \%)$ in our sample. Professions that were vulnerable to depression were other medical staff and students. Doctors, nurses, and students were vulnerable to anxiety; and other medical staff, students, and economy staff were vulnerable to stress. Coping strategies were reduced to three factors: active, mental, and emotional. Being female and emotional coping were independently associated with depression, anxiety, or stress. Applying active coping strategies showed lower odds for anxiety while mental coping strategies showed lower odds for depression, anxiety, and stress. Age, being inside a lockdown area, exposure to COVID-19 at work, and having a high workload (8-12 hours per day) were not associated with depression, anxiety, or stress. WeChat was the preferred way of staying informed across all groups.

Conclusions: By the end of the lockdown, a considerable part of the Chinese population showed increased levels of depression and anxiety. Students and other medical staff were the most affected, while economy staff were highly stressed. Doctors and nurses need support regarding potential anxiety disorders. Future work should focus on longitudinal results of the pandemic and develop targeted preventive measures. 


\section{KEYWORDS}

mental health; COVID-19; China; depression; anxiety; lockdown; coping strategies; stressors; stress; doctors; nurses; students; media consumption; WeChat

\section{Introduction}

\section{Background}

In December 2019, pneumonia cases of unknown etiology in Wuhan, Hubei Province, were reported by Chinese authorities. By January 3, 2020, 44 cases requiring hospitalization were officially confirmed [1]. The disease was titled COVID-19 by the World Health Organization in February 2020 [2]. As the infection spread rapidly all over the country [3], the public health response of the government included the largest quarantine in China's history. Starting from January 23, the lockdown in Hubei Province, the epicenter of COVID-19, lasted 76 days and ended on April 8, 2020 [4]. Zhejiang was another province that was put under lockdown [5].

The pandemic put a considerable psychological burden on citizens, which was not simply due to fear of infection but also isolation, helplessness, and grief over the loss of relatives without having the opportunity to take leave or to organize a funeral. Even more aggravating was that trusted persons, like family and friends, could be infected, and thus, became part of an invisible danger [6].

Previous epidemics, like the severe acute respiratory syndrome (SARS) in Hong Kong in 2003 or the Middle East respiratory syndrome (MERS) in Saudi Arabia in 2012, have taught us to care for the mental health of the general population and frontline health care workers [7-10]. In Hong Kong, suicide rates among older adults increased significantly in 2003 and 2004 [11]. It is noteworthy to recall that high-risk health workers suffered from long-lasting depression and posttraumatic stress responses even 1 year after the SARS outbreak [12].

\section{Mental Health and Coping Strategies}

Several studies have investigated the mental health consequences of the ongoing pandemic in the Chinese population and its strategies to successfully cope with the demanding situation. Wang et al [13] found increased anxiety in nearly 30\% of 1210 participants, especially caused by worrying about family members. The same authors also reported longitudinal results, repeating the measures after 4 weeks in March 2020 [14], and found no changes in the scores despite increased infection rates. A high level of trust in doctors and health information, as well as personal protective measures, was rated as helpful. The harmful effects of hoarding food and medicine were described as being associated with elevated levels of depression at the beginning of the crisis [15]. Another study found that cognitive coping behavior (eg, obtaining knowledge about COVID-19) and prosocial coping styles (eg, adherence to social distancing) proved to be protective for the population [16]. These authors described the high impact of the pandemic on the livelihood of the population and examined the harmful effects of media exposure on mental health.

Besides the obvious impact of the pandemic on mental health like the fear of infection and isolation due to quarantine measures [17], excessive media consumption was linked to mood disorders during the lockdown in China [18,19]. However, little is known about the influence of media preferences on the mental health of the population during the crisis.

\section{The Mental Health of Vulnerable Groups During COVID-19}

Since health care workers at the frontline were exposed to particularly demanding conditions during the peak of the pandemic, their mental health and coping strategies have become an early issue of concern. One of the first studies on this topic focused on medical and nursing staff in Wuhan and found elevated levels of subthreshold mental health disturbances in nearly $40 \%$ of the 994 participants surveyed [20]. A nationwide study in February reported nearly 5\% of medical and nonmedical staff with moderate and high levels of anxiety and about $13 \%$ with depression [21]. In this study, nurses and young personnel were found to be particularly at risk for mental distress. A nationwide survey by the end of February showed even higher levels (anxiety: 13\%; depression: 12\%; insomnia: 38\%) for doctors and nurses compared to nonmedical health workers [22]. Risk factors included living in a rural area, being female, and exposure to COVID-19. Additionally, health care workers were burdened by specific clinical and nonclinical stressors (eg, fear of bringing the virus home to family members and the experience of losing colleagues) [23].

There were some specific results on the psychological burden felt by nurses. Nurses in Anhui showed strong emotional responses. Increased exposure to COVID-19 cases evoked more anxiety and anger [24]. Increased levels of insomnia were reported among nurses in Wuhan, which might have been caused by comorbid sleep apnea due to stress [25]. Despite showing symptoms of severe distress, these Wuhan nurses refused to accept psychological help at the beginning of the pandemic [26].

Another vulnerable group included students, the majority of whom lived in quarantine with their families and reported victimization by facing or witnessing various stressful events related to COVID-19 [27]. Other studies found that the COVID-19 crisis impacted sleep quality [28], and increased anxiety among students was reported even after the lockdown ended [29]. Teachers were also affected not only by the outbreak but also by the stress experienced by their pupils [30].

In spite of the many studies regarding the mental health of the general population and health care workers on the frontline of the pandemic, we found no data on further vulnerable groups and professions that may be mentally or emotionally affected by indirect means. Although Huang and Zhao [31] found comparable depressive symptoms among employees in enterprises as in health care workers, and Wang et al $[13,14]$ reported longitudinal results in February and March, these results were from the initial stages of the lockdown and data from the end of the lockdown are missing to date. 


\section{Objectives of the Study}

The aim of this survey study was to assess the psychological burden of COVID-19 on the mental health of the Chinese population during the last 4 weeks of the lockdown in Hubei Province. We examined different professions in order to find vulnerable groups, possible influencing factors, and successful ways of coping. Moreover, we looked for specific stressors among doctors and nurses.

\section{Methods}

\section{Study Design}

We used a cross-sectional online survey design in order to investigate the impact of the COVID-19 pandemic on the mental health, stress, specific stressors, and coping strategies of different groups of the Chinese population. The study team of Heidelberg University Hospital developed the concept and the questionnaire, which was translated into Chinese. Its implementation into an online format and sampling was carried out by a publicity enterprise in Wuhan. The Tongji Medical College of the Huazhong University of Science and Technology supported the study by disseminating the link. The study started on March 19 and data were included until April 7. The lockdown in Hubei was officially ended on April 8 by the government [4].

Ethical approval for this study was granted by the Ethics Commission of the Medical Faculty of Heidelberg (S-361/2020). We followed the reporting guidelines of the STROBE (Strengthening the Reporting of Observational Studies in Epidemiology) statement for observational studies [32].

\section{Measures}

The questionnaire was derived from validated instruments and structured into four major parts. The first part asked for demographic data (place of residence, gender, age, marital status, educational background, and occupation), exposure to people infected with COVID-19 in general and at work, working hours per day, and media platforms used to obtain information (multiple choice). The second part asked for mental health parameters like depression, anxiety, and stress, measured by a shortened version of the 21-item Depression, Anxiety and Stress Scale (DASS-21) using a 4-point Likert scale [33]. We used the validated Chinese translation [34]. The instrument refers to a time span of the past week and has been shown to distinguish well between symptoms of depression, anxiety, and stress in clinical and nonclinical samples [35]. In order to assess stress levels during the past month, we used the 14-item Perceived Stress Scale (PSS-14) that explicitly refers to a longer time span using a 5-point Likert scale [36]. Again, we used a validated translation (ie, CPSS-14) [37]. The third part of our questionnaire targeted health care workers only and consisted of a questionnaire that was used in a former study on the SARS outbreak in 2003 [38]. The items asked for specific disease-related stressors of doctors and nurses and were rated on a 4-point Likert scale ( $0=$ not at all; $1=$ slightly; $2=$ moderately; $3=$ very much). Finally, the fourth part was again available for all participants and asked for successful coping strategies. The items were again taken from the SARS study [38] and recorded the frequency of use of various coping strategies on a 4-point scale $(0=$ almost never; $1=$ sometimes; $2=$ often; $3=$ almost always). Both scales were translated by a Chinese native speaker (JD).

\section{Data Analysis}

The responses of the participants were downloaded from the online survey tool and further processed and analyzed using SPSS 24 (IBM Corp) [39]. We collected 1006 data sets and removed all data sets that were filled out after April $7(n=74)$ and all questionnaires filled out in less than 513 seconds $(n=226)$, which corresponded to the lowest percentile of the mean processing time for all samples. In these cases, we assumed a lack of credibility if a participant took less than this amount of time. Finally, we removed all participants who were younger than the legal age $(n=7)$ and who were not in China during the survey $(n=9)$. We calculated descriptive statistics and reported frequencies, means, standard deviations, and percentages.

Participants answering from Hubei and Zhejiang provinces were regarded as being affected by the lockdown $(n=460)$. All other participants were not directly affected by the lockdown $(n=226)$.

The scoring of the DASS-21 are calculated as sum scores that have to be multiplied by two. The total depression subscale score was divided into normal (0-9), mild (10-13), moderate (14-20), severe (21-27), and extremely severe depression (28+). The anxiety subscale score was divided into normal (0-7), mild (8-9), moderate (10-14), severe (15-19), and extremely severe anxiety $(20+)$. The total stress subscale score was divided into normal (0-14), mild (15-18), moderate (19-25), severe (26-33), and extremely severe stress (34+). Next, we grouped the levels of severity into normal-mild and moderate-extremely severe for each score. We decided to put mild symptoms into one group together with the normal level, since we considered mild symptoms of depression and anxiety to exist regardless of the pandemic [40].

The CPSS-14 scores were calculated by sum scores as well. We reported the CPSS-14 scores and DASS-21 scores nationwide for each profession. For deeper analysis we calculated Pearson correlations in order to assess the relationship of perceived stress during the past 4 weeks and mental health scores for depression, anxiety, and stress during the past week.

The coping strategies and major stressors were calculated as means and standard deviations. We carried out a factor analysis (principal component analysis [PCA] with varimax rotation) for all coping strategies. The Kaiser-Meyer-Olkin (KMO) and Bartlett Test indicated a sufficient cohesion of the variables $(\mathrm{KMO}=0.76)$ [41]. Finally, binary logistic regression models were calculated and thereby investigated the associations of gender, lockdown area, contact with COVID-19 infections at work, and coping strategies (factors) with the odds of belonging to moderate-extremely severe depression, anxiety, or stress group. A nonsignificant value of $P=.40$ in the Hosmer-Lemeshow test indicated the goodness of fit of the models [42], and a Nagelkerkes $\mathrm{R}^{2}$ of 0.17 showed an acceptable coefficient of determination [41].

In all analyses, $P$ values $<.05$ were considered statistically significant. 


\section{Results}

\section{Participants}

The sample included 687 participants, $72.3 \%(n=496)$ of whom were female and $27.7 \%$ were $(n=190)$ male. The mean age was 36.92 years (SD 9.83) with a range of 18-71 years. The participants consisted of doctors $(n=158,23.0 \%)$, nurses $(n=221$, $32.2 \%)$, other medical staff $(n=24,3.5 \%)$, students $(n=43,6.6 \%)$, teachers/government staff $(n=60,8.7 \%)$, economy staff $(n=135$, $19.7 \%)$, workers/farmers $(n=26,3.8 \%)$, and others $(n=20,2.9 \%)$.
We combined doctors and dentists into one category. Other medical staff referred to health care professionals who were not doctors or nurses. Economy staff consisted of employees and self-employed individuals in the IT (information technology) and finance sectors.

A majority of the participants were from Hubei Province ( $n=449$, $65.4 \%) ; 30(4.4 \%)$ came from Jiangsu and 21 (3.1\%) each from Shanxi and Guangdong. A small group $(n=11,1.6 \%)$ came from Zhejiang, which was affected by a lockdown like Hubei. Demographic characteristics and details of each professional group are summarized in Table 1. 
Table 1. Demographic characteristics of the study participants.

\begin{tabular}{|c|c|}
\hline Characteristics & Participants, n (\%) \\
\hline Age (years), mean (SD) & $36.92(9.83)$ \\
\hline \multicolumn{2}{|l|}{ Gender } \\
\hline Male & $190(27.7)$ \\
\hline Female & $496(72.3)$ \\
\hline \multicolumn{2}{|l|}{ Family status } \\
\hline Single & $146(21.3)$ \\
\hline Married & $501(72.9)$ \\
\hline Divorced & $30(4.4)$ \\
\hline Widowed & $2(0.3)$ \\
\hline In a relationship & $8(1.2)$ \\
\hline \multicolumn{2}{|l|}{ Children } \\
\hline Yes & 499 (72.6) \\
\hline No & $188(27.4)$ \\
\hline \multicolumn{2}{|l|}{ Level of education } \\
\hline Middle school & $10(1.5)$ \\
\hline High school & $25(3.6)$ \\
\hline Junior college & $168(24.5)$ \\
\hline Bachelor & $384(55.9)$ \\
\hline Master & $77(11.2)$ \\
\hline Doctorate & $23(3.3)$ \\
\hline \multicolumn{2}{|l|}{ Profession } \\
\hline Doctors/dentists & $158(23.0)$ \\
\hline Nurses & $221(32.2)$ \\
\hline Other medical staff (eg, volunteers, pharmacists, midwives) & $24(3.5)$ \\
\hline Students & $43(6.3)$ \\
\hline Teachers/government staff & $60(8.7)$ \\
\hline Economy (eg, employees, self-employed, salespersons) & $135(19.7)$ \\
\hline Workers/farmers & $26(3.8)$ \\
\hline Others (eg, housewives) & $20(2.9)$ \\
\hline \multicolumn{2}{|l|}{ Residence } \\
\hline Hubei & $449(65.4)$ \\
\hline Jiangsu & $30(4.4)$ \\
\hline Guangdong & $21(3.1)$ \\
\hline Shanxi & $21(3.1)$ \\
\hline Shandong & $17(2.5)$ \\
\hline Fujian & $16(2.3)$ \\
\hline Sichuan & $15(2.2)$ \\
\hline Shanghai & $15(2.2)$ \\
\hline Hunan & $14(2.0)$ \\
\hline Zhejiang & $11(1.6)$ \\
\hline Provinces with less than 10 participants & $78(11.2)$ \\
\hline Total & $687(100)$ \\
\hline
\end{tabular}




\section{Perceived Stress and Mental Health}

Perceived stress was measured with a mean score of 23.70 (SD 7.52). The mean values for DASS-21 depression was 6.62 (SD 7.80), for DASS-21 anxiety was 7.01 (SD 7.00), and for DASS-21 stress was 10.18 (SD 8.63). Perceived stress was significantly correlated with DASS-21 depression $(r=0.61$,
$P<.001)$, DASS-21 anxiety $(r=0.57, P<.001)$, and DASS-21 stress $(r=0.66, P<.001)$.

Findings on mental health status for each profession are reported in Table 2; the DASS-21 scores were put into categories normal-mild and moderate-extremely severe.

Table 2. Results of the Simplified Chinese version of the 14-item Perceived Stress Scale (CPSS-14) and the Depression, Anxiety and Stress Scale 21 Items (DASS-21).

\begin{tabular}{|c|c|c|c|c|c|c|c|c|}
\hline \multirow[t]{2}{*}{ Profession } & \multirow[t]{2}{*}{ Participants, n } & \multicolumn{2}{|l|}{ CPSS-14 } & \multicolumn{2}{|c|}{ DASS-21 depression } & \multirow{2}{*}{$\begin{array}{l}\text { DASS-21 anxi- } \\
\text { ety } \\
\text { MES, n (\%) }\end{array}$} & \multicolumn{2}{|c|}{ DASS-21 stress } \\
\hline & & Mean (SD) & $\mathrm{NM}^{\mathrm{a}}, \mathrm{n}(\%)$ & $\mathrm{MES}^{\mathrm{b}}, \mathrm{n}(\%)$ & NM, n (\%) & & NM, n (\%) & $\begin{array}{l}\text { MES, n } \\
(\%)\end{array}$ \\
\hline Doctors & 158 & $23.16(7.26)$ & $134(84.8)$ & $24(15.2)$ & $106(67.1)$ & $52(32.9)$ & $138(87.3)$ & $20(12.5)$ \\
\hline Nurses & 221 & $23.62(7.19)$ & $183(82.8)$ & $38(17.2)$ & $152(68.8)$ & $69(31.2)$ & $197(89.1)$ & $24(10.9)$ \\
\hline Other medical staff & 24 & 22.25 (8.09) & $19(79.2)$ & $5(20.8)$ & $17(70.8)$ & $7(29.2)$ & $20(83.3)$ & $4(16.7)$ \\
\hline Students & 43 & $26.30(7.79)$ & $33(76.7)$ & $10(23.3)$ & $25(58.1)$ & $18(41.9)$ & $34(79.1)$ & $9(20.9)$ \\
\hline $\begin{array}{l}\text { Teachers/ } \\
\text { govt staff }\end{array}$ & 60 & $22.98(6.09)$ & $51(85.0)$ & $9(15.0)$ & $44(73.3)$ & $16(26.7)$ & $53(88.3)$ & $7(11.7)$ \\
\hline Economy staff & 135 & $23.93(8.68)$ & $108(79.4)$ & $27(20.0)$ & $102(75.6)$ & $33(24.4)$ & $112(83.0)$ & $23(17.0)$ \\
\hline Workers/farmers & 26 & $23.15(6.69)$ & $21(77.8)$ & $5(19.2)$ & $19(73.1)$ & $7(26.9)$ & $23(85.5)$ & $3(11.5)$ \\
\hline Others & 20 & $26.25(7.62)$ & $15(75.0)$ & $5(25.0)$ & $14(70.0)$ & $6(30.0)$ & $16(80.0)$ & $4(20.0)$ \\
\hline Total & 687 & $23.70(7.52)$ & $564(82.1)$ & $123(17.9)$ & 479 (69.7) & $208(30.3)$ & $593(86.3)$ & $94(13.7)$ \\
\hline
\end{tabular}

a NM: normal-mild.

${ }^{\mathrm{b}} \mathrm{MES}$ : moderate-extremely severe.

\section{Working Hours Per Day}

The majority of the participants reported working 4-8 hours per day $(n=427,61.4 \%)$. This was the case in the following groups-nurses: 145/221, 65.6\%; students: 39/43, 90.7\%; teachers/government staff: $47 / 60,78.4 \%$; economy staff: $97 / 135$, $71.9 \%$; workers/farmers: $18 / 26,69.3 \%$; others: $15 / 20,75.0 \%$.

A sizeable part of the sample reported working 8-12 hours per day $(n=260,37.4 \%)$. This high workload typically affected doctors $(103 / 158,65.2 \%)$ and other medical staff $(13 / 24$, $54.2 \%)$

\section{Contact With COVID-19 at Work}

In total, $6(0.9 \%)$ participants were infected themselves (2 doctors, 3 nurses, and 1 member of the group teachers/government staff). Of all participants, 180 (26.2\%) had contact with people infected by the virus at work. The most affected group were doctors $(68 / 158,43.0 \%$ had contact with COVID-19 at work), followed by other medical staff (10/24, $41.7 \%)$, nurses $(88 / 221,39.8 \%)$, teachers/government staff $(8 / 60,13.3 \%)$, economy staff $(5 / 135,3.8 \%)$, workers/farmers $(1 / 26,3.8 \%)$. Participants from the other professions category and students did not report contact with COVID-19 at work.

\section{Media Preferences}

When asked about the primary way participants obtained information in the past month, the majority of respondents indicated having done so through WeChat $(n=606,88.2 \%)$ (Table 3). 
Table 3. Participants' answers to the multiple-choice question: what was your main way of obtaining information during the last month?

\begin{tabular}{ll}
\hline Source & Participants, $\mathrm{n}(\%)$ \\
\hline Newspaper & $53(7.71)$ \\
Television & $465(67.69)$ \\
Weibo & $304(44.25)$ \\
WeChat & $606(88.21)$ \\
Circle of friends ${ }^{\mathrm{a}}$ & $502(73.07)$ \\
Family/colleagues & $311(45.27)$ \\
Other & $104(15.14)$ \\
\hline
\end{tabular}

${ }^{\mathrm{a}}$ Includes WeChat groups and other social media-related groups.

\section{Coping Strategies}

The three most successful ways of facing the demands of COVID-19 in daily life and work, out of 12 possible answers, were taking protective measures (mean 2.57, SD 0.67), actively acquiring more knowledge about COVID-19 (mean 2.09, SD
0.78), and engaging in recreational activities (mean 1.94, SD 0.77). All coping strategies are listed in Table 4.

Three dimensions could be extracted after carrying out the PCA and were named as active coping, mental coping, and emotional coping, after analyzing the content of the items. The dimensions accounted for $47.2 \%$ of the variance (Table 4 ).

Table 4. Matrix of coping strategy components and three statistics after varimax rotation (the rotation is converged in five iterations; method of extraction: main component analysis).

\begin{tabular}{|c|c|c|c|c|}
\hline \multirow[t]{2}{*}{ Items } & \multirow[t]{2}{*}{ Mean (SD) } & \multicolumn{3}{|c|}{ Factor loadings } \\
\hline & & Active & Mental & Emotiona \\
\hline \multicolumn{5}{|l|}{ Coping strategy components } \\
\hline $\begin{array}{l}\text { Taking protective measures (washing hands, wearing a mask, taking one's own } \\
\text { temperature, etc) }\end{array}$ & $2.57(0.67)$ & 0.77 & -0.03 & 0.01 \\
\hline $\begin{array}{l}\text { Actively acquiring more knowledge about COVID-19 (symptoms, transmission } \\
\text { pathway, etc) }\end{array}$ & $2.09(0.78)$ & 0.75 & 0.17 & 0.02 \\
\hline Changing one's thoughts and facing the situation with a positive attitude & $1.90(0.83)$ & 0.53 & 0.44 & -0.12 \\
\hline $\begin{array}{l}\text { Engaging in recreational activities (WeChat, Weibo, TikTok, online shopping, } \\
\text { online movies, exercises) }\end{array}$ & $1.94(0.77)$ & 0.42 & 0.23 & -0.06 \\
\hline Video chatting with family and friends by phone to share concerns and support & $1.69(0.80)$ & 0.40 & 0.43 & -0.02 \\
\hline Engaging in health-promoting behaviors (more rest, exercise, balanced diet, etc) & $1.76(0.82)$ & 0.27 & 0.68 & -0.06 \\
\hline Acquiring mental health knowledge and information & $1.36(0.91)$ & 0.27 & 0.63 & 0.01 \\
\hline Practicing relaxation methods (meditation, yoga, Tai Chi, etc) & $0.88(0.85)$ & -0.07 & 0.83 & 0.09 \\
\hline Limiting oneself from watching too much news about COVID-19 & $0.53(0.73)$ & -0.11 & 0.13 & 0.72 \\
\hline $\begin{array}{l}\text { Distracting oneself from thinking about COVID-19 issues by suppression or } \\
\text { keeping busy }\end{array}$ & $0.70(0.82)$ & 0.03 & 0.10 & 0.75 \\
\hline Venting emotions by crying, screaming, smashing things, and so on & $0.23(0.48)$ & -0.08 & -0.08 & 0.53 \\
\hline Using alcohol or drugs & $0.22(0.53)$ & 0.07 & -0.10 & 0.53 \\
\hline \multicolumn{5}{|l|}{ Statistics } \\
\hline Eigenvalue & $-^{\mathrm{a}}$ & 2.89 & 1.71 & 1.07 \\
\hline Percentage of total variance & - & 24.05 & 14.23 & 8.93 \\
\hline Total variance & - & - & - & 47.21 \\
\hline
\end{tabular}

${ }^{\mathrm{a}}$ Not applicable. 
Predictors of Increased Levels of Depression, Anxiety, and Stress

We calculated three binary logistic regression models in order to find associations of gender, lockdown area, contact with COVID-19 infection at work, and coping factors with the odds of belonging to the group for moderate-extremely severe depression, anxiety, or stress. Being female and applying emotional coping strategies increased the probability of belonging to the moderate-extremely severe depression, anxiety, or stress group. Applying active coping strategies reduced the probability of being affected by moderate-extremely severe anxiety, while mental coping strategies reduced the probability in all three moderate-extremely severe mental health groups. Age, being in a lockdown area, having contact with COVID-19 at work, and having a high workload (8-12 hr per day) did not significantly predict the odds of expressing moderate-extremely severe symptoms of depression, anxiety, or stress. The results are displayed in detail in Table 5.

Table 5. Results of a logistic regression predicting the probability of experiencing moderate-extremely severe (MES) depression, anxiety, or stress.

\begin{tabular}{lllllll}
\hline Variable & \multicolumn{2}{l}{ MES depression } & MES anxiety & & \multicolumn{2}{l}{ MES stress } \\
& B (SE) & OR $^{\mathrm{a}}(95 \% \mathrm{CI})$ & $\mathrm{B}(\mathrm{SE})$ & OR $(95 \% \mathrm{CI})$ & B (SE) & OR (95\% CI) \\
\hline Gender (female) & $0.81(0.27)$ & $2.24(1.33-3.77)$ & $0.47(0.22)$ & $1.61(1.05-2.47)$ & $0.78(0.30)$ & $2.19(1.21-3.96)$ \\
Age & $0.01(0.01)$ & $1.01(0.98-1.03)$ & $-0.01(0.01)$ & $0.99(0.97-1.00)$ & $-0.01(0.01)$ & $0.99(0.96-1.01)$ \\
Hubei/Zhejiang & $-0.43(0.25)$ & $0.65(0.40-1.05)$ & $-0.07(0.21)$ & $0.93(0.61-1.41)$ & $-0.22(0.28)$ & $0.80(0.46-1.39)$ \\
Contact with COVID-19 & $0.07(0.26)$ & $1.08(0.64-1.80)$ & $0.15(0.49)$ & $1.16(0.76-1.79)$ & $-0.03(0.30)$ & $0.97(0.54-1.74)$ \\
infection at work & & & & & $0.32(0.25)$ & $1.38(0.85-2.25)$ \\
Daily workload (8-12 hr) & $0.06(0.22)$ & $1.06(0.69-1.65)$ & $0.23(0.19)$ & $1.26(0.87-1.83)$ & $-0.11(0.12)$ & $0.89(0.70-1.13)$ \\
Active coping & $-0.14(0.11)$ & $0.87(0.71-1.07)$ & $-0.21(0.09)$ & $0.81(0.68-0.97)$ & $-0.12)$ \\
Mental coping & $-0.56(0.12)$ & $0.57(0.45-0.72)$ & $-0.42(0.10)$ & $0.67(0.55-0.81)$ & $-0.67(0.14)$ & $0.51(0.39-0.67)$ \\
Emotional coping & $0.63(0.10)$ & $1.89(1.55-2.30)$ & $0.80(0.10)$ & $2.16(1.80-2.60)$ & $0.82(0.11)$ & $2.27(1.81-2.84)$ \\
\hline
\end{tabular}

${ }^{\mathrm{a} O R}$ : odds ratio.

\section{Major Stressors (Health Care Workers Only)}

Out of 18 stressors, the three most demanding aspects for health care workers $(n=375)$ were related to worries about infecting one's family with COVID-19 (mean 1.46, SD 0.86), followed by the potential deterioration of their patients' condition (mean 1.42, SD 0.79) and their patients' emotional reaction (mean 1.3, SD 0.81) (Table 6). 
Table 6. Doctors' and nurses' responses to the question: when you think about COVID-19 in your life and work, how often did you think or worry about the following things? $(0=$ not at all, $3=$ very much $)(n=375)$.

\begin{tabular}{|c|c|}
\hline Stressor & Response, mean (SD) \\
\hline Worries about infecting your family with COVID-19 & $1.46(0.86)$ \\
\hline Deterioration of patients' condition & $1.42(0.79)$ \\
\hline Patients' emotional reaction & $1.30(0.81)$ \\
\hline Emotional reaction of patients' families & $1.29(0.79)$ \\
\hline Uncertainties about when the epidemic will be under control & $1.27(0.78)$ \\
\hline Coworkers displaying COVID-19-like symptoms & $1.27(0.79)$ \\
\hline Worries about getting infected & $1.24(0.78)$ \\
\hline Worries about being negligent and endangering patients & $1.23(0.88)$ \\
\hline Worries about lack of proper knowledge and equipment & $1.23(0.79)$ \\
\hline Worries about being negligent and endangering coworkers & $1.18(0.83)$ \\
\hline Worries about nosocomial spread & $1.15(0.82)$ \\
\hline Conflict between duty and safety & $1.15(0.81)$ \\
\hline Being infected by colleagues & $1.12(0.81)$ \\
\hline Protective gears being a hinderance to providing quality care & $1.12(0.80)$ \\
\hline Being blamed by supervisors/managers & $1.10(0.80)$ \\
\hline Displaying COVID-19-like symptoms yourself & $1.09(0.77)$ \\
\hline Worries about the lack of manpower & $1.07(0.91)$ \\
\hline Being without a properly equipped environment & $1.05(0.84)$ \\
\hline Physical discomfort caused by protective gears & $1.01(0.79)$ \\
\hline Ambiguity in the responsibilities between doctors and nurses & $1.00(0.86)$ \\
\hline Frequent modification of infection control procedures & $0.96(0.81)$ \\
\hline Coworkers being emotionally unstable & $0.96(0.77)$ \\
\hline Unclear documentation and reporting procedures & $0.92(0.78)$ \\
\hline
\end{tabular}

\section{Discussion}

\section{Predictors of Mental Health Symptoms}

This survey aimed to assess the psychological burden and mental health of the Chinese population during the final stages of the lockdown, as well as to determine successful coping strategies and potentially vulnerable professional groups with specific support needs. Our results suggest that being female and, independent of gender, applying certain coping strategies increased the incidence of symptoms of depression, anxiety, and stress. Emotional coping strategies like venting emotions, consuming alcohol, or limiting oneself from information were not helpful for participants dealing with COVID-19-related psychological problems. Active strategies to cope with moderate-extremely severe anxiety, such as taking protective measures and acquiring more knowledge were more beneficial, but the most effective strategy was focusing on mental coping like relaxation techniques and gaining knowledge about mental health. Our results confirm the findings of Guo et al [16], who used another instrument to determine coping strategies but found emotion-focused strategies to worsen mental health, while cognitive and problem-focused coping strategies to be helpful. Interestingly, exposure to COVID-19 at work, living within a lockdown area, and daily workload did not play a significant role in predicting elevated symptoms.

We found no overall increased mean values in perceived stress and depression, anxiety, and stress in comparison to former (pre-COVID-19) samples (eg, compared to the perceived stress levels of patients in Hong Kong [43] or among residents in Beijing [44]) regarding mental health scores. This could be because the Chinese population had already become accustomed to the burden of COVID-19 by the end of the lockdown. The first studies in January investigating the psychological impact of the outbreak on the population reported high levels of burden $[16,31,45]$. Wang et al $[13,14]$ measured DASS-21 scores twice at the beginning and at the peak of the pandemic in China and found increased anxiety in nearly $30 \%$ of participants; yet no longitudinal increases were noted. In our study, we added a third point of measurement at the final stage of the lockdown and found a considerable share of people who expressed moderate to extremely severe symptoms of depression (17.9\%), anxiety (30.3\%), and stress (13.7\%). This result should be taken seriously as our sample revealed a higher percentage of people with increased levels of depression while stress scores were lower compared to the Wang et al $[13,14]$ studies. We also observed a high correlation of perceived stress in the past 4 weeks and actual scores in depression. Previous research on the 
etiology of depression could show that stress might be one predictor for this mood disorder [46,47]. Following this line of argument, an increase of depressive symptoms by the end of the lockdown could be interpreted as part of a concerning development.

\section{Vulnerable Groups}

Some groups in our sample were more affected by symptoms of depression, anxiety, or stress than others. Students were vulnerable to moderate-extremely severe symptoms in all three categories. Outside the pandemic context, Chinese students have been reported to be affected by mental health problems due to stressful academic demands $[48,49]$. The consequences of the pandemic on students' lives were aggravated by infection control measures, online learning on a tight schedule, and uncertain future prospects [50]. A cross-sectional study among medical students after the lockdown revealed high levels of anxiety (38\% of participants) and showed that social media played an important role in adherence to protective measures among them [29]. According to our results, the main method of getting COVID-19-related information was WeChat, directly followed by circle of friends, which in China refers to WeChat groups and other social media-related groups.

Economy staff were highly burdened by stress but did not exhibit more depression or anxiety than other groups. This result does not support that of Huang and Zhao [31], who, using different protocols, questioned enterprise employees in early February, and found depression among $20 \%$ of participants and anxiety among $34 \%$. Increased stress levels in our sample could be explained by the fact that we put together all employees and self-employed people in the finance and IT sectors as well as salespersons in one group. Enhanced stress may be a result of the concerns to ensure livelihood for their own family during the lockdown, as shown previously [16]. Further differentiated results are needed to allow for a more specific statement.

Doctors and nurses in our sample were highly affected by anxiety; doctors had the highest workload per day. Nevertheless, perceived stress and DASS-21 stress levels were not higher than other groups, which may be due to a high professional devotion, as reported in previous research [51]. Issues about patient care like the deterioration of the patients' condition and the emotional reaction of patients and their families were perceived as stressful. In another study, nurses in Wuhan were found lacking in training for dealing with uncooperative patients [26]. Several studies have reported on the need for training Chinese medical staff on doctor-patient communication outside the context of the COVID-19 crisis [52]. The anxiety felt by doctors and nurses in our sample may be the result of the fear of bringing COVID-19 to their own families, the most intense stressor in our and other samples [23,51]. A further stressor found in other studies included spending too much time on social media while searching for COVID-19 updates. Doing so promoted symptoms of depression and anxiety in Chinese adults in general as well as in health professionals [19].

Finally, other medical staff, a small group consisting of volunteers, midwives, and pharmacists in our sample, was more affected by depression and stress than other groups and was vulnerable to anxiety as well. During the pandemic, many volunteers supported hospitals in a frontline capacity [53], and our results show that these individuals, who had the second highest workload per day after doctors, have been overlooked so far and should receive more attention since they seem to have special support needs. This group might lack the institutional psychological support that is delivered to the core personnel in a frontline hospital.

\section{Future Implications}

By 2017, there were only 33,400 licensed psychiatrists in China [54]. In recent years, the Chinese National Health Commission has established several mental health initiatives to extend mental health care to the general population. During the COVID-19 pandemic, the commission published guidelines and treatment instructions, uploaded videos of mental health education via WeChat, and established expert emergency groups for mental health services at the hospitals [55].

However, health care workers continue to be in dire need of greater access to specific mental health services [56], and further research is needed on the role of media consumption and mental health during such crises. Although the internet provided many supporting measures like telemedicine for patients with COVID-19 [57] and online mental health education and counseling [58], excessive exposure to the media seems to play a significant role in explaining mental health problems during the pandemic [18]. The Chinese population might find itself in a paradox: acquiring knowledge about the virus and mental health measures is helpful but in order to maximize coverage this knowledge is spread by governmental and other institutions via social media [55,58], which has its own harmful mental consequences [16,19]. As a result, it is not possible for individuals to avoid media consumption. More conclusive findings on the role of the media and the mental health of subgroups of the Chinese population are needed.

\section{Limitations}

Although we received 687 responses, the professional groups in this study were not of equal size; numbers were especially limited for the students and other medical staff categories, which reduces the power of statistical analysis. Targeted investigations may be needed to assess the status of underrepresented professions in a differentiated way. Further, online studies are unable to allow a valuable diagnostic assessment, and this limitation applies to all former studies. This is further aggravated due to the great variability in instruments used in different surveys, which reduces the comparability of results. Some authors used the DASS-21 previously $[13,14]$ but with different cut off-scores (see below), while some relied on the Self-rating Depression Scale (SDS) [45], the Patient Health Questionnaire (PHQ) [56], the Generalized Anxiety Disorder 7-item (GAD-7), the Center for Epidemiology Scale for Depression (CES-D) [31], or the Post-Traumatic Stress Disorders (PTSD) Checklist [16]. However, only a face-to-face diagnostic interview by a qualified medical doctor or a clinical psychologist could allow a statement regarding a mental disorder. Therefore, our results hint at a certain development but should not be interpreted as a diagnosis of the population. Moreover, we compared our results to the studies of Wang et al [13,14], who used slightly different cut-off scores in interpreting the borders between mild 
and moderate depression and anxiety as suggested originally by Lovibond and Lovibond [33]. However, even without knowing their exact frequencies for single scores, our findings on increases in depression would have been even higher if Wang et al had used the original cut-off scores. Finally, we only asked for media preferences and not for the time spent on media platforms. A detailed analysis on the reasons for media consumption (entertainment, information, relaxation), the way of usage (alone, together), and mental health is necessary to reveal a more holistic picture.

\section{Conclusion}

A considerable part of the general population in China reported elevated symptoms of depression, anxiety, and stress during the final stages of the COVID-19 lockdown. Doctors, nurses, students, and other medical staff were found to be in imminent danger of developing mental health problems. Similarly, economy staff was also highly stressed. Being female was an additional risk factor for potential vulnerability toward developing mental health problems. We recommend providing additional specific information to these subgroups targeting their respective mental health profile and to personalize the successful coping strategies found in our results (ie, active and mental coping). These refer to constructive ways of behavior (eg, actively acquiring knowledge, applying protective measures) and mental health strategies (eg, relaxation techniques, psycho-education, and promoting social contact). Profession-specific mental health prevention programs should be developed and provided in formats preferred by the respective age, gender, or professional groups.

\section{Acknowledgments}

We thank all participants for taking part in our study despite the current challenges imposed by the pandemic. We also thank Wuhan CNweb Pioneer Ltd, which was responsible for the implementation of the online survey in collaboration with the QHealth Trusted Doctors Group (Penguin), Wuhan Saidian Consulting Service Company, and Tao Doctor APP. We appreciate the support of Tongji Medical College for disseminating the questionnaire link.

\section{Conflicts of Interest}

None declared.

\section{References}

1. Pneumonia of unknown cause - China. World Health Organization. 2020 Jan 5. URL: https://www.who.int/csr/don/ 05-january-2020-pneumonia-of-unkown-cause-china/en/ [accessed 2020-08-01]

2. Timeline of WHO's response to COVID-19. World Health Organization. 2020 Jun 29. URL: https://www.who.int/news-room/ detail/29-06-2020-covidtimeline [accessed 2020-08-01]

3. Wu Z, McGoogan JM. Characteristics of and Important Lessons From the Coronavirus Disease 2019 (COVID-19) Outbreak in China: Summary of a Report of 72314 Cases From the Chinese Center for Disease Control and Prevention. JAMA 2020 Apr 07;323(13):1239-1242. [doi: 10.1001/jama.2020.2648] [Medline: 32091533]

4. Desheng C. Wuhan reopens after 76-day lockdown. Chinadaily. 2020 Apr 8. URL: http://www.chinadaily.com.cn/a/202004/ 08/WS5e8d06fca310aeaeeed5099e.html [accessed 2020-08-01]

5. Fifield A. Hundreds of miles from Hubei, additional 30 million Chinese are in coronavirus lockdown. The Washington Post. 2020 Feb 7. URL: https://www.washingtonpost.com/world/asia pacific/ hundreds-of-miles-from-hubei-another-30-million-chinese-are-in-coronavirus-lockdown/2020/02/07/ 03a08282-48b9-11ea-8a1f-de1597be6cbc story.html [accessed 2020-08-01]

6. Fiorillo A, Gorwood P. The consequences of the COVID-19 pandemic on mental health and implications for clinical practice. Eur Psychiatry 2020 Apr 01;63(1):e32 [FREE Full text] [doi: 10.1192/j.eurpsy.2020.35] [Medline: 32234102]

7. Tam CWC, Pang EPF, Lam LCW, Chiu HFK. Severe acute respiratory syndrome (SARS) in Hong Kong in 2003: stress and psychological impact among frontline healthcare workers. Psychol Med 2004 Oct 21;34(7):1197-1204. [doi: 10.1017/s0033291704002247] [Medline: 15697046 ]

8. Maunder R, Hunter J, Vincent L, Bennett J, Peladeau N, Leszcz M, et al. The immediate psychological and occupational impact of the 2003 SARS outbreak in a teaching hospital. CMAJ 2003 May 13;168(10):1245-1251 [FREE Full text] [Medline: 12743065]

9. Khalid I, Khalid TJ, Qabajah MR, Barnard AG, Qushmaq IA. Healthcare Workers Emotions, Perceived Stressors and Coping Strategies During a MERS-CoV Outbreak. Clin Med Res 2016 Mar 04;14(1):7-14 [FREE Full text] [doi: 10.3121/cmr.2016.1303] [Medline: 26847480]

10. Park J, Lee E, Park N, Choi YH. Mental Health of Nurses Working at a Government-designated Hospital During a MERS-CoV Outbreak: A Cross-sectional Study. Arch Psychiatr Nurs 2018 Feb;32(1):2-6 [FREE Full text] [doi: 10.1016/j.apnu.2017.09.006] [Medline: 29413067]

11. Cheung YT, Chau PH, Yip PSF. A revisit on older adults suicides and Severe Acute Respiratory Syndrome (SARS) epidemic in Hong Kong. Int J Geriatr Psychiatry 2008 Dec;23(12):1231-1238. [doi: 10.1002/gps.2056] [Medline: 18500689]

12. McAlonan GM, Lee AM, Cheung V, Cheung C, Tsang KW, Sham PC, et al. Immediate and sustained psychological impact of an emerging infectious disease outbreak on health care workers. Can J Psychiatry 2007 Apr 23;52(4):241-247. [doi: 10.1177/070674370705200406] [Medline: 17500305] 
13. Wang C, Pan R, Wan X, Tan Y, Xu L, Ho CS, et al. Immediate Psychological Responses and Associated Factors during the Initial Stage of the 2019 Coronavirus Disease (COVID-19) Epidemic among the General Population in China. IJERPH 2020 Mar 06;17(5):1729. [doi: 10.3390/ijerph17051729]

14. Wang C, Pan R, Wan X, Tan Y, Xu L, McIntyre RS, et al. A longitudinal study on the mental health of general population during the COVID-19 epidemic in China. Brain Behav Immun 2020 Jul;87:40-48 [FREE Full text] [doi: 10.1016/j.bbi.2020.04.028] [Medline: 32298802]

15. Zhang W, Yang X, Zhao J, Yang F, Jia Y, Cui C, et al. Depression and Psychological-Behavioral Responses Among the General Public in China During the Early Stages of the COVID-19 Pandemic: Survey Study. J Med Internet Res 2020 Sep 04;22(9):e22227 [FREE Full text] [doi: 10.2196/22227] [Medline: 32886066]

16. Guo J, Feng X, Wang X, van IJzendoorn MH. Coping with COVID: Exposure to COVID-19 and Negative Impact on Livelihood Predict Elevated Mental Health Problems in Chinese Adults. SSRN Journal 2020 Apr 29 [FREE Full text] [doi: 10.2139/ssrn.3592667]

17. Shah K, Kamrai D, Mekala H, Mann B, Desai K, Patel RS. Focus on Mental Health During the Coronavirus (COVID-19) Pandemic: Applying Learnings from the Past Outbreaks. Cureus 2020 Mar 25;12(3):e7405 [FREE Full text] [doi: 10.7759/cureus.7405] [Medline: $\underline{32337131]}$

18. Gao J, Zheng P, Jia Y, Chen H, Mao Y, Chen S, et al. Mental health problems and social media exposure during COVID-19 outbreak. PLoS One 2020 Apr 16;15(4):e0231924 [FREE Full text] [doi: 10.1371/journal.pone.0231924] [Medline: $\underline{32298385}$

19. Ni MY, Yang L, Leung CMC, Li N, Yao XI, Wang Y, et al. Mental Health, Risk Factors, and Social Media Use During the COVID-19 Epidemic and Cordon Sanitaire Among the Community and Health Professionals in Wuhan, China: Cross-Sectional Survey. JMIR Ment Health 2020 May 12;7(5):e19009 [FREE Full text] [doi: 10.2196/19009] [Medline: 32365044]

20. Kang L, Li Y, Hu S, Chen M, Yang C, Yang BX, et al. The mental health of medical workers in Wuhan, China dealing with the 2019 novel coronavirus. The Lancet Psychiatry 2020 Mar;7(3):e14. [doi: 10.1016/s2215-0366(20)30047-x]

21. Guo J, Liao L, Wang B, Li X, Guo L, Tong Z, et al. Psychological Effects of COVID-19 on Hospital Staff: A National Cross-Sectional Survey of China Mainland. SSRN Journal 2020 Mar 13 [FREE Full text] [doi: 10.2139/ssrn.3550050]

22. Zhang W, Wang K, Yin L, Zhao W, Xue Q, Peng M, et al. Mental Health and Psychosocial Problems of Medical Health Workers during the COVID-19 Epidemic in China. Psychother Psychosom 2020 Apr 9;89(4):242-250 [FREE Full text] [doi: $10.1159 / 000507639]$ [Medline: $\underline{32272480]}$

23. Hall $\mathrm{H}$. The effect of the COVID-19 pandemic on healthcare workers' mental health. JAAPA 2020 Jul;33(7):45-48. [doi: 10.1097/01.JAA.0000669772.78848.8c] [Medline: 32590533]

24. Huang L, Xu F, Liu H. Emotional responses and coping strategies of nurses and nursing college students during COVID-19 outbreak. medRxiv 2020 Preprint posted online March 08, 2020. [doi: 10.1101/2020.03.05.20031898]

25. Zhuo K, Gao C, Wang X, Zhang C, Wang Z. Stress and sleep: a survey based on wearable sleep trackers among medical and nursing staff in Wuhan during the COVID-19 pandemic. Gen Psych 2020 Jun 16;33(3):e100260. [doi: 10.1136/gpsych-2020-100260]

26. Chen Q, Liang M, Li Y, Guo J, Fei D, Wang L, et al. Mental health care for medical staff in China during the COVID-19 outbreak. The Lancet Psychiatry 2020 Apr;7(4):e15-e16. [doi: 10.1016/s2215-0366(20)30078-x]

27. Yang D, Tu C, Dai X. The effect of the 2019 novel coronavirus pandemic on college students in Wuhan. Psychol Trauma 2020 Aug;12(S1):S6-S14. [doi: 10.1037/tra0000930] [Medline: 32551764]

28. Zhang Y, Zhang H, Ma X, Di Q. Mental Health Problems during the COVID-19 Pandemics and the Mitigation Effects of Exercise: A Longitudinal Study of College Students in China. Int J Environ Res Public Health 2020 May 25;17(10):3722 [FREE Full text] [doi: 10.3390/ijerph17103722] [Medline: 32466163]

29. Lin Y, Hu Z, Alias H, Wong LP. Influence of Mass and Social Media on Psychobehavioral Responses Among Medical Students During the Downward Trend of COVID-19 in Fujian, China: Cross-Sectional Study. J Med Internet Res 2020 Jul 20;22(7):e19982 [FREE Full text] [doi: 10.2196/19982] [Medline: 32584779]

30. Zhou X. Managing psychological distress in children and adolescents following the COVID-19 epidemic: A cooperative approach. Psychol Trauma 2020 Aug;12(S1):S76-S78. [doi: 10.1037/tra0000754] [Medline: 32551769]

31. Huang Y, Zhao N. Generalized anxiety disorder, depressive symptoms and sleep quality during COVID-19 outbreak in China: a web-based cross-sectional survey. Psychiatry Res 2020 Jun;288:112954 [FREE Full text] [doi:

10.1016/j.psychres.2020.112954] [Medline: 32325383]

32. von Elm E, Altman DG, Egger M, Pocock SJ, Gøtzsche PC, Vandenbroucke JP, STROBE Initiative. The Strengthening the Reporting of Observational Studies in Epidemiology (STROBE) statement: guidelines for reporting observational studies. Ann Intern Med 2007 Oct 16;147(8):573-577 [FREE Full text] [doi: 10.7326/0003-4819-147-8-200710160-00010] [Medline: 17938396]

33. Lovibond SH, Lovibond PF. Manual for the Depression Anxiety Stress Scales. Sydney, NSW: Psychology Foundation of Australia; 1996.

34. Zuo K, Chang A. Zuo and Chang Chinese translation (simplified characters). Psychology Foundation of Australia. URL: http://www2.psy.unsw.edu.au/dass//Chinese/Chinese\%20simplified.htm [accessed 2020-08-01] 
35. Antony MM, Bieling PJ, Cox BJ, Enns MW, Swinson RP. Psychometric properties of the 42-item and 21-item versions of the Depression Anxiety Stress Scales in clinical groups and a community sample. Psychological Assessment 1998 Jun;10(2):176-181. [doi: 10.1037/1040-3590.10.2.176]

36. Cohen S, Kamarck T, Mermelstein R. A Global Measure of Perceived Stress. Journal of Health and Social Behavior 1983 Dec;24(4):385. [doi: 10.2307/2136404]

37. Shi C, Guo Y, Ma H, Zhang M. Psychometric validation of the 14-item perceived stress scale in Chinese medical residents. Curr Psychol 2019 May 27;38(6):1428-1434. [doi: 10.1007/s12144-019-00285-y]

38. Lee S, Juang Y, Su Y, Lee H, Lin YH, Chao C. Facing SARS: psychological impacts on SARS team nurses and psychiatric services in a Taiwan general hospital. Gen Hosp Psychiatry 2005 Sep;27(5):352-358 [FREE Full text] [doi: 10.1016/j.genhosppsych.2005.04.007] [Medline: 16168796]

39. SPSS Statistics for Windows. Armonk, NY: IBM Corp; 2016.

40. Sartorius N, Üstün TB, Lecrubier Y, Wittchen H. Depression Comorbid with Anxiety: Results from the WHO Study on Psychological Disorders in Primary Health Care. Br J Psychiatry 2018 Aug 06;168(S30):38-43. [doi: $10.1192 / \mathrm{s} 0007125000298395]$

41. Backhaus K, Erichson B, Plinke W, Weiber R. Multivariate Analysemethoden. Berlin, Heidelberg: Springer Gabler; 2016.

42. Fagerland MW, Hosmer DW. A goodness-of-fit test for the proportional odds regression model. Stat Med 2013 Jun 15;32(13):2235-2249. [doi: 10.1002/sim.5645] [Medline: 23037691]

43. Leung DY, Lam T, Chan SS. Three versions of Perceived Stress Scale: validation in a sample of Chinese cardiac patients who smoke. BMC Public Health 2010 Aug 25;10(1):513 [FREE Full text] [doi: 10.1186/1471-2458-10-513] [Medline: 20735860]

44. Chan RC, Xu T, Huang J, Wang Y, Zhao Q, Shum DH, et al. Extending the utility of the Depression Anxiety Stress scale by examining its psychometric properties in Chinese settings. Psychiatry Res 2012 Dec 30;200(2-3):879-883. [doi: 10.1016/j.psychres.2012.06.041] [Medline: 22921506]

45. Chen B, Li Q, Zhang H, Zhu J, Yang X, Wu Y, et al. The psychological impact of COVID-19 outbreak on medical staff and the general public. Curr Psychol 2020 Oct 07:1-9. [doi: 10.1007/s12144-020-01109-0] [Medline: 33046955]

46. Vinkers CH, Joëls M, Milaneschi Y, Kahn RS, Penninx BW, Boks MP. Stress exposure across the life span cumulatively increases depression risk and is moderated by neuroticism. Depress Anxiety 2014 Sep 17;31(9):737-745. [doi: 10.1002/da.22262] [Medline: 24753162]

47. Ménard C, Hodes G, Russo S. Pathogenesis of depression: Insights from human and rodent studies. Neuroscience 2016 May 03;321:138-162 [FREE Full text] [doi: 10.1016/j.neuroscience.2015.05.053] [Medline: 26037806]

48. Lun KW, Chan C, Ip PK, Ma SY, Tsai W, Wong C, et al. Depression and anxiety among university students in Hong Kong. Hong Kong Med J 2018 Oct 24;24(5):466-472 [FREE Full text] [doi: 10.12809/hkmj176915] [Medline: $\underline{\text { 30245480] }}$

49. Mao Y, Zhang N, Liu J, Zhu B, He R, Wang X. A systematic review of depression and anxiety in medical students in China. BMC Med Educ 2019 Sep 02;19(1):327 [FREE Full text] [doi: 10.1186/s12909-019-1744-2] [Medline: 31477124]

50. Li HY, Cao H, Leung DYP, Mak YW. The Psychological Impacts of a COVID-19 Outbreak on College Students in China: A Longitudinal Study. Int J Environ Res Public Health 2020 Jun 02;17(11):3933 [FREE Full text] [doi: 10.3390/ijerph17113933] [Medline: 32498267]

51. Wang H, Liu Y, Hu K, Zhang M, Du M, Huang H, et al. Healthcare workers' stress when caring for COVID-19 patients: An altruistic perspective. Nurs Ethics 2020 Nov 14;27(7):1490-1500. [doi: 10.1177/0969733020934146] [Medline: $\underline{32662326}$ ]

52. Liu X, Rohrer W, Luo A, Fang Z, He T, Xie W. Doctor-patient communication skills training in mainland China: a systematic review of the literature. Patient Educ Couns 2015 Jan;98(1):3-14. [doi: 10.1016/j.pec.2014.09.012] [Medline: 25308954]

53. Kanthor R. A New Generation of Volunteers Emerges in the Chinese City at the Epicenter of the Coronavirus Crisis. The Times. 2020 Feb 24. URL: https://time.com/5789530/wuhan-volunteers-coronavirus-covid-19-china/ [accessed 2020-08-01]

54. Duan L, Zhu G. Psychological interventions for people affected by the COVID-19 epidemic. The Lancet Psychiatry 2020 Apr;7(4):300-302. [doi: 10.1016/s2215-0366(20)30073-0]

55. Li W, Yang Y, Liu Z, Zhao Y, Zhang Q, Zhang L, et al. Progression of Mental Health Services during the COVID-19 Outbreak in China. Int J Biol Sci 2020;16(10):1732-1738 [FREE Full text] [doi: 10.7150/ijbs.45120] [Medline: 32226291]

56. Kang L, Ma S, Chen M, Yang J, Wang Y, Li R, et al. Impact on mental health and perceptions of psychological care among medical and nursing staff in Wuhan during the 2019 novel coronavirus disease outbreak: A cross-sectional study. Brain Behav Immun 2020 Jul;87:11-17 [FREE Full text] [doi: 10.1016/j.bbi.2020.03.028] [Medline: 32240764]

57. Hong Z, Li N, Li D, Li J, Li B, Xiong W, et al. Telemedicine During the COVID-19 Pandemic: Experiences From Western China. J Med Internet Res 2020 May 08;22(5):e19577 [FREE Full text] [doi: 10.2196/19577] [Medline: 32349962]

58. Liu S, Yang L, Zhang C, Xiang Y, Liu Z, Hu S, et al. Online mental health services in China during the COVID-19 outbreak. The Lancet Psychiatry 2020 Apr;7(4):e17-e18. [doi: 10.1016/s2215-0366(20)30077-8]

\section{Abbreviations \\ CES-D: Center for Epidemiology Scale for Depression \\ CPSS-14: Simplified Chinese version of the 14-item Perceived Stress Scale}


DASS-21: Depression, Anxiety and Stress Scale - 21 Items

GAD-7: Generalized Anxiety Disorder 7-item

KMO: Kaiser-Meyer-Olkin

MERS: Middle East respiratory syndrome

PCA: principal component analysis

PHQ: Patient Health Questionnaire

PSS-14: 14 -item Perceived Stress Scale

PTSD Checklist: Post-Traumatic Stress Disorders Checklist

SARS: severe acute respiratory syndrome

SDS: Self-rating Depression Scale

STROBE: Strengthening the Reporting of Observational Studies in Epidemiology

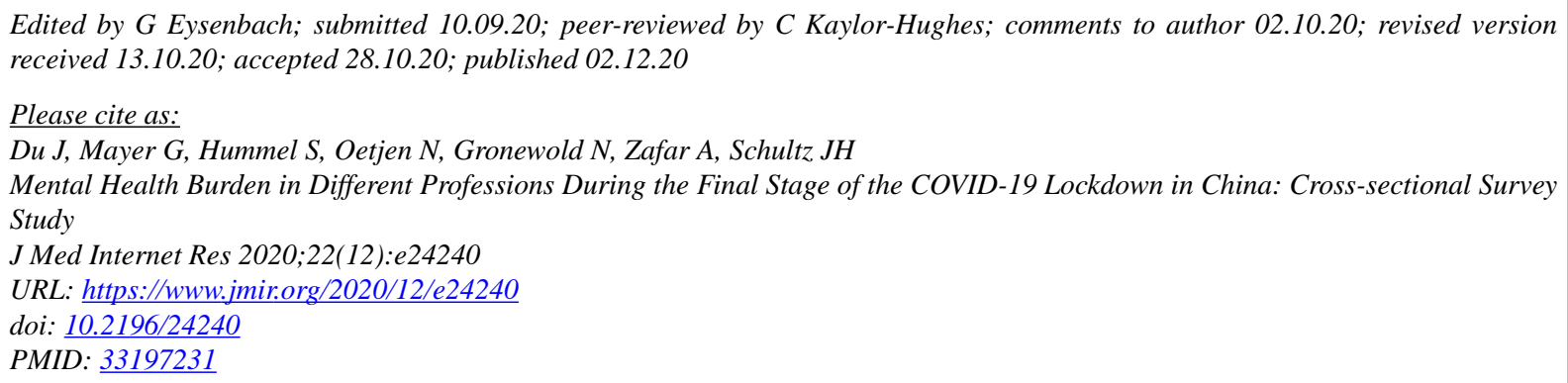

(CJunfeng Du, Gwendolyn Mayer, Svenja Hummel, Neele Oetjen, Nadine Gronewold, Ali Zafar, Jobst-Hendrik Schultz. Originally published in the Journal of Medical Internet Research (http://www.jmir.org), 02.12.2020. This is an open-access article distributed under the terms of the Creative Commons Attribution License (https://creativecommons.org/licenses/by/4.0/), which permits unrestricted use, distribution, and reproduction in any medium, provided the original work, first published in the Journal of Medical Internet Research, is properly cited. The complete bibliographic information, a link to the original publication on http://www.jmir.org/, as well as this copyright and license information must be included. 